\title{
In vitro and in vivo evaluation of prebiotic potential of pectin on vaginal lactobacilli
}

\author{
Sanjeevani Shekhar Deshkar*, Kiran Suresh Ahire, Jayashri Gajanan Mahore \\ Dr. D. Y. Patil Institute of Pharmaceutical Sciences and Research, Sant Tukaram Nagar, Pimpri, Pune, India.
}

\begin{tabular}{|c|c|}
\hline ARTICLE INFO & ABSTRACT \\
\hline $\begin{array}{l}\text { Article history: } \\
\text { Received on: September 04, } 2021 \\
\text { Accepted on: December 02, } 2021 \\
\text { Available online: January 07, } 2022\end{array}$ & $\begin{array}{l}\text { Lactobacilli are predominant microorganism in vaginal ecology and provide protection against pathogens. The } \\
\text { present study was aimed to evaluate the in vitro and in vivo prebiotic effect of pectin on vaginal lactobacilli. The } \\
\text { effect of pectin concentration on growth of Lactobacilli casei (LC) and Lactobacilli fermentum (LF) was studied by } \\
\text { measuring change in } \mathrm{pH} \text {, optical density, titratable acidity, and dry mass after } 48 \mathrm{~h} \text { of incubation. The antimicrobial }\end{array}$ \\
\hline $\begin{array}{l}\text { Key words: } \\
\text { Lactobacilli, } \\
\text { Pectin, } \\
\text { Prebiotic, } \\
\text { Vaginitis, } \\
\text { Vaginal flora. }\end{array}$ & $\begin{array}{l}\text { effect against pathogenic Escherichia coli and Candida albicans was studied by agar diffusion technique. In } \\
\text { vitro effect of pectin on viability of mixed cultures of LC or LF with } E \text {. coli or } C \text {. albicans was studied. In vivo, } \\
\text { prophylactic and therapeutic effect of pectin on vaginal lactobacilli was investigated on female Wistar rats. The } \\
\text { stimulative effect of pectin was confirmed by an increase in LC and LF dry mass, reduction in pH, and increase in } \\
\text { production of organic acid. Lactobacilli supernatants showed a significant antimicrobial effect against } E \text {. coli. The } \\
\text { mixed culture study demonstrated the stimulative effect of pectin on LC and LF, whereas inhibitory effects on } E \text {. } \\
\text { coli and } C \text {. albicans. In vivo study on female rats revealed a significant increase in lactobacilli count in vaginal flora } \\
\text { after topical administration of pectin. This study demonstrated the prophylactic and therapeutic effect of pectin as a } \\
\text { prebiotic on vaginal microflora. }\end{array}$ \\
\hline
\end{tabular}

\section{INTRODUCTION}

The microflora of healthy human vagina is composed of dominant Lactobacilli species that play an important role in promoting vaginal health [1]. Lactobacilli are an integral part of vaginal defense mechanism and provide protection against pathogens by the formation of biofilm on vaginal epithelium, secretion of organic acids, and production of antimicrobial substances, and stimulation of immune system of host [2]. Any change in local microflora of vagina leads to a condition known as dysbiosis that is indicated by a decrease in lactobacilli count and increase in the growth of pathogenic bacteria [3]. Recently much interest has been focused on alternative therapies for treatment of vaginal infection, considering the adverse effects of current antimicrobial agents on vaginal ecology. Use of probiotic and prebiotic is a potential area of research for promoting vaginal health $[4,5]$.

Prebiotics are insoluble dietary fibers that are known to stimulate the growth of health-promoting endogenous microorganisms like lactobacilli affecting the composition of natural microflora [6]. Probiotics as per WHO are defined as "live micro-organisms which when administered in adequate amount confer the health benefits

\footnotetext{
*Corresponding Author

Sanjeevani Shekhar Deshkar,

Dr. D. Y. Patil Institute of Pharmaceutical Sciences and Research,

Sant Tukaram Nagar, Pimpri, Pune - 411 018, India.

E-mail: sanjeevanisd@yahoo.com
}

to the host." The mechanisms which are identified for the probiotic action are: Promotion of lactobacilli growth, competition of lactobacilli with pathogens for adhesion to epithelial cells and for nutrients, production of antimicrobials such as bacteriocin, hydrogen peroxides, and restoration of vaginal $\mathrm{pH}$ by production of lactic acid that is unfavorable to growth of pathogens and by modulating local immunological responses [7].

The pro and prebiotic approach has been widely studied in treatment of gastrointestinal infectious diseases, inflammatory bowel disease like ulcerative colitis [8], Chrohn's disease [9] and also in prevention of colon cancer [10]. Although there are limited reports on prebiotic and synbiotic approach for promoting vaginal health, use of probiotic for vaginal health is reported by both oral and topical route $[11,12]$ and had supported the possibility of restoration of vaginal microbiota after oral administration of lactobacilli. Clinical studies have reported the efficacy of probiotics in treatment and prevention of vaginal infections such as bacterial vaginosis [13], vaginal candidiasis [14], and urinary tract infections [15] when administered topically. Current reports on vaginal probiotics suggest that it may serve as an important approach for faster recovery and prevention of recurrences of vaginal infections [16].

Although probiotic seems to be an interesting approach, maintaining stability of probiotic formulation is challenging. Moreover, for topical applications of probiotic, limited dosage forms are available that would retain stability and efficacy of probiotic bacteria. Use of prebiotic that has a stimulating effect on local microflora may serve as an alternative 
approach to probiotic. However, most of the reported studies of prebiotic in literature are associated with colonic function. Prebiotics are reported to show change in the composition of short-chain fatty acids, decrease local $\mathrm{pH}$, decrease reductive enzymes, and play important role in immunomodulation [7]. The short-chain fatty acids produced by fermentation of prebiotics affect mucosal inflammation, colonization of pathogens, enzymatic activities, chemoprevention in carcinogenesis, etc. Prebiotics are also reported to play an important role in apoptosis of human tumor cells [17]. There are very few reports on the use of prebiotic carbohydrates for vaginal infections. Recent reports by Sutherland et al. (2008) [18] have indicated the possibility of prevention of vaginal infections such as bacterial vaginosis and candidiasis by topical application of prebiotics. Rousseau et al. (2005) [19] reported beneficial effect of fructo-oligosaccharides and gluco-oligosaccharides on growth of vaginal lactobacilli by in vitro models. A clinical study by Coste et al. (2012) [12] indicated recovery of normal vaginal flora in patients treated with gels containing glucooligosaccharides. In one of our previous studies, the in vitro effect of fructo- and galacto-oligosaccharides on vaginal lactobacilli such as Lactobacilli acidophilus, Lactobacilli casei (LC), and Lactobacilli fermentum (LF) was investigated [20]. In the present study, an attempt has been made to investigate the in vitro and in vivo effect of pectin on vaginal lactobacilli. Pectin is a soluble hetero-polysaccharide obtained from ripe fruits and is mainly used as viscosity modifier or gelling agent in food industry [21]. It is also a by-product obtained from fruit wastes. It mainly contains colloidal poly (galacturonic acid) with varying degree of methylation [22]. Previous research has supported the role of pectin as prebiotic for gastrointestinal flora [23]. To the best of our knowledge, there are no reports in the literature depicting effect of pectin on vaginal microflora, although pectin has been used previously as a carrier for vaginal drug delivery [24]. In view of this, in the present study, effect of pectin on two vaginal lactobacilli strains, LC, and LF was evaluated by measuring their growth kinetics in the presence of pectin and antimicrobial effects of these lactobacilli against Escherichia coli and Candida albicans, commonly observed pathogens of the genitourinary tract, was also evaluated. The prophylactic and therapeutic effect of pectin on vaginal microflora was studied using in vivo rat model.

\section{MATERIALS AND METHODS}

\subsection{Materials}

LF (ATCC 14931) and LC (ATCC 393) were provided by the Department of Biotechnology, Dr. D. Y. Patil Science College, Pune. E. coli (ATCC 8739) and C. albicans (ATCC 10231) were provided by the Department of Microbiology, Dr. D.Y. Patil Medical College, Pune. Citrus fruit pectin was obtained as a gift sample from Krishna Pectin Jalgaon, India. All the media and chemicals were of analytical grade and purchased from HiMedia, Mumbai, India.

\subsection{Methods}

\subsubsection{Microbial strains, media, and growth condition}

For the present study, microbial cultures of LF (ATCC 14931), LC (ATCC 393), E. coli (ATCC 8739), and C. albicans (ATCC 10231) were used. Lactobacilli strains were cultured in deMan-RogosaSharpe (MRS) broth or in reconstituted MRS broth and incubated at $37^{\circ} \mathrm{C}$ for $24 \mathrm{~h}$ in microaerophilic condition using candle jar. In candle jar method, a candle was placed in a desiccator containing plates such that the candle utilized the oxygen present in the desiccator to create a condition with low oxygen content. E. coli was cultured in MacConkey broth at $37^{\circ} \mathrm{C}$ for $24 \mathrm{~h}$ and C. albicans was subcultured in potato dextrose broth at $37^{\circ} \mathrm{C}$ for $24 \mathrm{~h}$ in aerobic condition. For all the study protocols, an overnight $(18 \mathrm{~h})$ culture of each microbial strain was used.

\subsubsection{Preparation of lactobacilli strains}

For the preparation of LC and LF culture, a single colony of lactobacilli previously-stored at $-20^{\circ} \mathrm{C}$ on MRS agar plate was transferred to $30 \mathrm{ml}$ of MRS broth and incubation was carried out at $37^{\circ} \mathrm{C}$ for $18 \mathrm{~h}$ in microaerophilic condition. The broth was centrifuged to obtain a pellet. The pellet was further re-suspended in MRS broth to obtain the turbidity of suspension adjusted to $0.5 \mathrm{McF}$ arland standards. The inoculum concentration was considered to be approximately 1.5 $\times 10^{6} \mathrm{cfu} / \mathrm{ml}$ as per inoculum density.

\subsubsection{Effect of pectin on growth of lactobacilli}

The growth kinetic of lactobacilli was carried out in MRS broth and reconstituted MRS broth supplemented with pectin. In MRS broth, the cultivation of LC and LF was conducted with addition of $2 \%$ $(\mathrm{v} / \mathrm{v})$ of the inoculum in $250 \mathrm{ml}$ of sterile MRS broth aseptically. The flasks were then incubated at $37^{\circ} \mathrm{C}$ for $48 \mathrm{~h}$ in anaerobic condition. Samples were collected after every $2 \mathrm{~h}$ to determine optical density at $600 \mathrm{~nm}$ [20]. Each experiment was conducted in triplicate.

\subsubsection{Determination of dry biomass}

To monitor the process of cellular growth and to establish the relationship of optical density at $600 \mathrm{~nm}$ and dry biomass, broth samples were centrifuged at $4000 \mathrm{rpm}$ in a cooling centrifuge (Remi, C24, India) for $30 \mathrm{~min}$. The cell-free supernatants were preserved for further testing. The settled pellets were collected and weighed. The pellets were dried in hot air oven at $80^{\circ} \mathrm{C}$ till their weight remained constant. The final weight was taken as dry biomass weight. Calibration curve of optical density and dry biomass was plotted and a linear equation was obtained. This equation was used to plot the growth curves and maximum specific growth rate $(\mu \mathrm{max})$ and doubling time $\left(\mathrm{t}_{\mathrm{d}}\right)$ was calculated from the growth curves [20,25].

\subsection{5. $\mathrm{pH}$}

The $\mathrm{pH}$ was measured by a calibrated electronic digital $\mathrm{pH}$ meter (Equip-Tronic, EQ-614A, India).

\subsubsection{Determination of Titratable acidity}

The acid production (\% Titratable acidity) of LC and LF was determined by titrating the supernatant samples with $0.1 \mathrm{M} \mathrm{NaOH}$ using phenolphthalein as an indicator. The titratable acidity was calculated [26] as follows,

$$
\text { üüüüüüüüü } \quad=\frac{\mathrm{N} \mathrm{X} \mathrm{V} \mathrm{X} \mathrm{M}}{\mathrm{S} \mathrm{X10}}
$$

Where, $\mathrm{N}=$ Normality of standard $\mathrm{NaOH}$ used for titration $\mathrm{V}=$ volume of standard $\mathrm{NaOH}$ used for titration in $\mathrm{mL}$

$\mathrm{M}=$ Molecular weight of predominant acid in the sample divided by the number of hydrogen ions in the acid molecules that are titrated $\mathrm{S}=$ Sample size in $\mathrm{mL}$ or $\mathrm{g}$.

\subsubsection{Determination of antimicrobial activity against $E$. coli and C. albicans}

Antimicrobial activity of cell-free supernatant from LC and LF cultures was tested against $E$. coli and C. albicans by agar well diffusion method. For E. coli and C. albicans, MacConkey agar and potato dextrose agar were used, respectively. The media were prepared and sterilized at $121^{\circ} \mathrm{C}$ for $20 \mathrm{~min}$ in an autoclave. The sterilized media were poured into sterile Petri plates and allowed to solidify under 
aseptic conditions. The overnight cultures $(0.1 \mathrm{ml})$ of $E$. coli and $C$. albicans were spread uniformly on respective agar media. The cups were cut using bore of $6 \mathrm{~mm}$ diameter and $0.1 \mathrm{ml}$ of supernatants was added to each well. The samples were allowed to diffuse for $4 \mathrm{~h}$ in the refrigerator followed by incubation of plates at $37^{\circ} \mathrm{C}$ for $24 \mathrm{~h}$ for E. coli and $48 \mathrm{~h}$ for C. albicans in aerobic conditions. The tests were performed in triplicate and zones of inhibition were measured [27].

\subsubsection{In vitro investigation of pectin efficacy by mixed culture technique}

Minimal essential medium (MEM, $100 \mathrm{ml}$ ) consisting of yeast extract, peptone, bile salt, vitamin K, cysteine, Tween 80 , and supplemented with $3 \% \mathrm{w} / \mathrm{v}$ of pectin as a sole carbon source was sterilized and inoculated with overnight cultures of lactobacilli and pathogenic bacteria (E. coli and C. albicans). Flask I was inoculated with LF and $E$. coli, flask 2 with $\mathrm{LF}$ and $C$. albicans, flask 3 with $\mathrm{LC}$ and E. coli, and flask 4 with LC and C. albicans. The media was incubated for $48 \mathrm{~h}$ under microaerophilic conditions. After 0,24 , and $48 \mathrm{~h}$, $100 \mu \mathrm{l}$ of suspension was removed from flask, and serial dilutions $\left(10^{-1}, 10^{-2}, 10^{-4}, 10^{-6}, 10^{-8}, 10^{-10}\right)$ were prepared using sterile broth. The dilutions $(100 \mu \mathrm{l})$ were plated on sterile agar plates and incubated at $37^{\circ} \mathrm{C}$ in incubator for $24 \mathrm{~h}$. For lactobacilli, MRS agar was used, for E. coli, MacConkey's agar, and C. albicans were plated on potato dextrose agar medium. After $24 \mathrm{~h}$ of incubation, colonies on each plate were counted using digital colony counter to estimate the total viable count [28]. The viable count of $(\mathrm{cfu} / \mathrm{ml})$ was calculated using following formula.

$$
\mathrm{cfu} / \mathrm{ml}=\frac{\text { No of colonies } / \mathrm{ml} \text { plated }}{\text { Dilution factor }}
$$

\subsubsection{In vivo effect of pectin on vaginal lactobacilli flora}

To study the prophylactic and therapeutic effect of pectin on vaginal lactobacilli flora, an experimental rat model was developed in our laboratory. This model is not reported previously in the literature for vaginal route. All the animal experiments in the study were approved by Institutional Animal Ethical Committee and were strictly adhering to CPCSEA guidelines of India (DYPIPSR/IAEC/17-18/P-15). For this model, 7-8 weeks old female Wistar rats were used. Rats received a normal diet and water ad libitum and were kept in isolation at temperature of $25^{\circ} \mathrm{C}$ with $12 \mathrm{~h}$ light and dark cycle. The lactobacilli viable count of rat vagina was studied by taking vaginal swabs. The vaginal smear was serially diluted aseptically with sterile saline and plating was done using MRS agar. The plates were incubated at $37^{\circ} \mathrm{C}$ for $48 \mathrm{~h}$. The rats with lactobacilli population equal to or more than 1.5 $\times 10^{6} \mathrm{cfu} / \mathrm{ml}$ and with no signs of infection were only considered for the study. Rats were divided in 4 groups each containing 6 animals. Out of four groups included in the study group, group 1 and group 2 were used to study the preventive effect of pectin as prebiotic, whereas group 3 and 4 were used in the experiment of therapeutic effect of prebiotic.

\subsubsection{Preventive effect}

To study the preventive or prophylactic effect of pectin on vaginal microflora, one group of animal (Group 2) was administered pectin gel $(3 \% \mathrm{w} / \mathrm{v})$ intravaginally $(100 \mu \mathrm{l})$ once daily for 28 days and group 1 was served as control which did not receive any prebiotic treatment. On $0\left(\mathrm{~T}_{0}\right), 7\left(\mathrm{~T}_{7}\right), 14\left(\mathrm{~T}_{14}\right), 21\left(\mathrm{~T}_{21}\right)$, and $28^{\text {th }}\left(\mathrm{T}_{28}\right)$ day, vaginal swabbing was done and after proper serial dilutions, plating was carried out MRS agar to determine the lactobacilli count. After 28 days, marketed metronidazole vaginal gel (Metrogyl Gel, 2\%w/w,
J. B. Chemicals and Pharmaceuticals Ltd., India) was administered intravaginally $(100 \mu \mathrm{l})$ to rats from both the groups (group 1 and 2) daily for 7 days to disturb the local microflora. The objective was to check the prophylactic activity of pectin as prebiotic against control group which was not given any prior treatment. After $3^{\text {rd }}\left(\mathrm{T}_{31}\right)$ and $7^{\text {th }}$ $\left(T_{35}\right)$ day of administration of Metronidazole, the vaginal lactobacilli count was determined and results were expressed as $\log \mathrm{cfu} / \mathrm{ml}$.

\subsubsection{Therapeutic effect}

This study was performed to investigate the ability of pectin as prebiotic to restore the disturbed vaginal flora. In this model, the vaginal flora of rats was first compromised and then the treatment was given by intravaginal administration of pectin. Group 3 and group 4 of rats were used for this study. The vaginal microflora of experimental rats in both the groups was compromised or disturbed by administering Metrogyl gel, intravaginally $(100 \mu \mathrm{l})$, for 7 days. The decrease in lactobacilli count was confirmed by determining viable lactobacilli count after 7 days $\left(\mathrm{T}_{7}\right)$ of gel administration. After confirmation of compromised vaginal flora, group 4 received prebiotic treatment once a daily for 28 days by intravaginal pectin gel administration (3\%w/v). Group 3 was treated as control and no treatment was given to this group. The viable lactobacilli count was determined on $7\left(\mathrm{~T}_{14}\right), 14\left(\mathrm{~T}_{21}\right), 21\left(\mathrm{~T}_{28}\right)$, and $28^{\text {th }}\left(\mathrm{T}_{35}\right)$ day of pectin administration. The vaginal swabs were cultured after serial dilution on MRS agar plates and incubated in microaerophilic conditions.

\subsubsection{Histopathological evaluation of vagina}

For the histological experiments, one animal of each group was sacrificed. The rats were euthanized by carbon dioxide inhalation. The vagina and uterine horns of each animal were removed and fixed in neutral-buffered Formalin. These tissues were trimmed longitudinally and tissue processing was done to dehydrate in ascending grades of alcohol, clearing in xylene, and embedded in paraffin wax. Paraffin wax embedded tissue blocks were sectioned at $5 \mu \mathrm{m}$ thickness with the rotary microtome. All the slides of vagina were stained with hematoxylin and eosin stain. The prepared slides were examined under microscope to note histopathological lesions and leukotriene infiltration, if any. Severity of observed lesions was recorded.

\subsection{Statistical Analysis}

The bacterial counts were log-transformed for each experiment and readings were expressed as mean $\pm \mathrm{SD}$. The statistical difference in the groups was determined by applying analysis of variance followed by unpaired $t$-test (GraphPad Instat 3, USA). The difference was considered as statistically significant for $P \leq 0.05$.

\section{RESULTS AND DISCUSSION}

\subsection{Effect of Pectin on Growth of Lactobacilli}

Effect of pectin on growth of LF and LC is shown in Figures 1 and 2. Addition of pectin had significant $(P<0.005)$ effect on the growth of LF as well as LC as compared to control. Maximum growth was observed during 2 to $28 \mathrm{~h}$. A significant difference in growth of lactobacilli was observed with change in concentration of pectin. An increase in pectin concentration from $1 \%$ to $3 \% \mathrm{w} / \mathrm{v}$ significantly increased the OD of LF and LC cultures which demonstrated the ability of pectin to stimulate lactobacilli growth. Further increase in pectin concentration (above 3\%) did not significantly increase OD of $\mathrm{LF}$ and $\mathrm{LC}$ as compared to $3 \%$ pectin. Hence, concentrations of pectin above $3 \%$ were not considered in the study. 


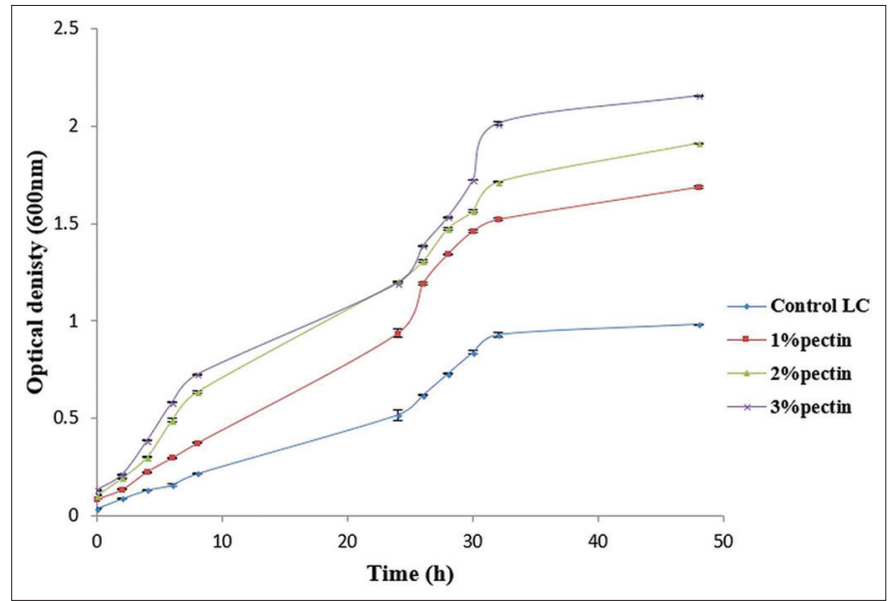

Figure 1: Effect of pectin on growth of Lactobacilli casei. *Error bars represent standard deviations of three replicates.

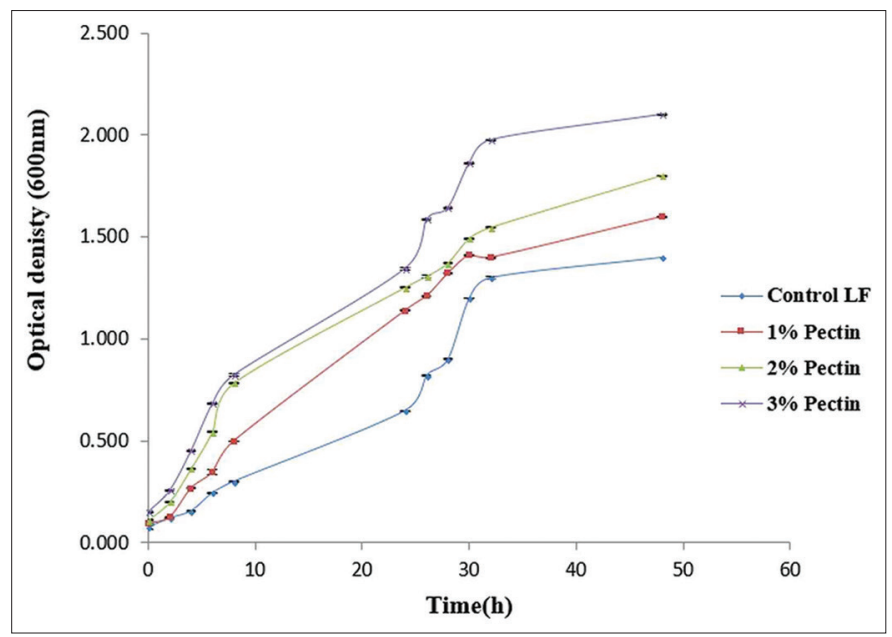

Figure 2: Effect of pectin on growth of Lactobacilli fermentum. *Error bars represent standard deviations of three replicates.

These results were further confirmed by the growth curves [Figures 3 and 4] with dry biomass $(\mathrm{g} / \mathrm{L})$ plotted as function of time. The cellular concentration expressed in terms of dry mass for Lactobacilli species increased with an increase in pectin concentration. The higher growth rate of LC ( $\mu$ max, $0.080 \mathrm{~g}$. $\mathrm{L}^{-1} \mathrm{~h}^{-1}$ ) than $\mathrm{LF}\left(\mu \max , 0.046 \mathrm{~g}\right.$. $\mathrm{L}^{-1} \mathrm{~h}^{-1}$ ) was further confirmed. The doubling time $\left(\mathrm{t}_{\mathrm{d}}\right)$ for LC and LF in the presence of pectin was 19.8 $\mathrm{h}$ and $34.6 \mathrm{~h}$, respectively.

The difference in the growth rate of LC and LF could be attributed to pectinolytic ability of both the lactobacilli strains. The lactobacilli have the ability to degrade the polysaccharide to monosaccharides that are used as a sugar source by lactobacilli for their growth [29]. The presence of a prebiotic-specific enzyme hydrolysis system is needed in lactobacilli for the utilization of any prebiotic by those lactobacilli [30]. The pectinolytic activities of lactobacilli had been reported in studies related to fermentation process; however, there are few reports identifying specific polysaccharide degrading enzymes in lactobacilli [29]. Recent reports have suggested that diversity of lactobacilli strains in carbohydrate fermentation could be attributed to phylogenetic diversity in the genus lactobacillus [30].

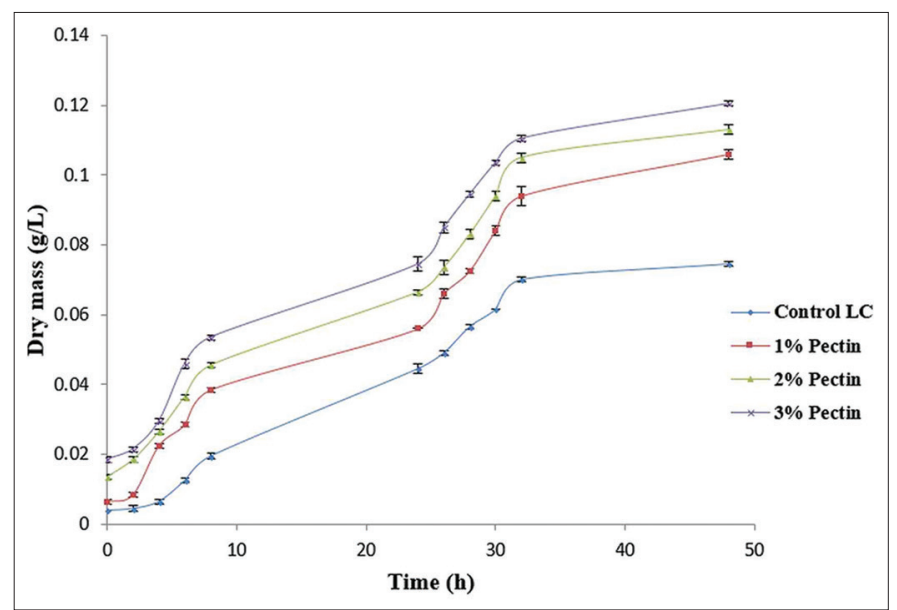

Figure 3: Effect of pectin on Lactobacilli casei dry biomass. *Error bars represent standard deviations of three replicates.

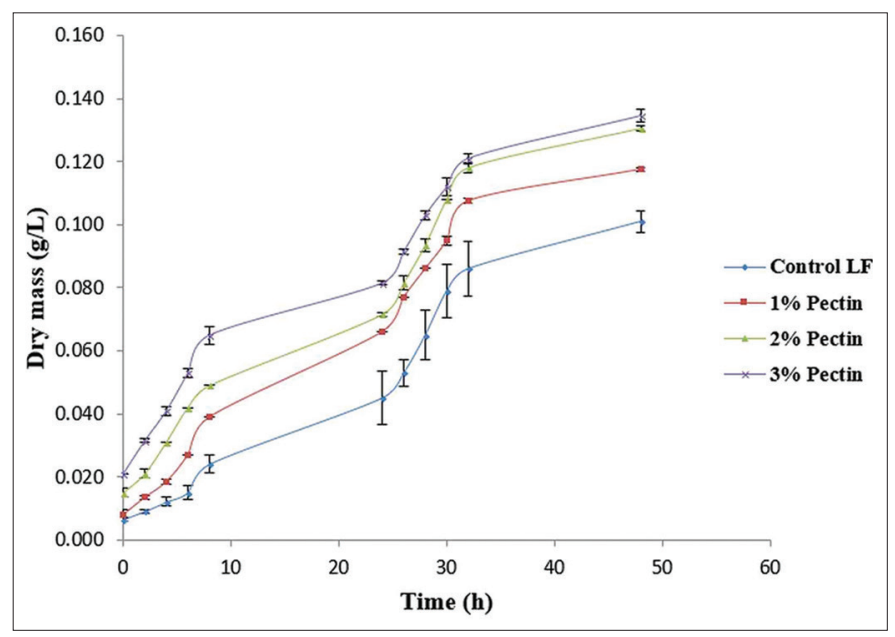

Figure 4: Effect of pectin on Lactobacilli fermentum dry biomass. *Error bars represent standard deviations of three replicates.

\subsection{Effect on Titratable Acidity}

Table 1 indicate titratable acidity (\%) produced by LC and LF in the presence and absence of pectin. The titratable acidity was found to be increased with an increase in pectin concentration. As lactobacilli produced different organic acid (lactic and acetic acid as predominant) through fermentation of glucose, in the presence of pectin, the availability of monosaccharide is more than control resulting in increased production of organic acid. The LC demonstrated higher acid production than LF. This is in agreement with several studies reported in literature [31,32]. Piwat et al. (2012) [33] classified LC as a strong acid producer, whereas LF belonging to medium acid-producing group. The acid-producing ability can be correlated with growth rate of lactobacilli strains. In this study, LC demonstrated higher growth rate and sugar fermenting ability resulting in higher acid production and lower $\mathrm{pH}$ compared to Lactobacilli fermentum (LF). LC is reported to utilize Embden-Meyerhof-Parnas and 6-phosphogluconate/phosphoketolase pathways to ferment sugar [20].

\subsection{Effect of $\mathrm{pH}$}

The effect of pectin on $\mathrm{pH}$ lowering capacity of lactobacilli is depicted in Table 1. As evident from the table, pectin demonstrated 
Table 1: The $\mathrm{pH}$ values, titratable acidity, and zone of inhibition of lactobacilli supernatants against Escherichia coli.

\begin{tabular}{|c|c|c|c|c|c|c|c|}
\hline \multirow[t]{2}{*}{ Incubation time (h) } & \multicolumn{4}{|c|}{ Lactobacilli casei } & \multicolumn{3}{|c|}{ Lactobacilli fermentum } \\
\hline & Carbon source & $\mathrm{pH} *$ & $\begin{array}{c}\text { Titratable } \\
\text { acidity }(\%)^{*}\end{array}$ & $\begin{array}{c}\text { Zone of } \\
\text { inhibition }(\mathrm{mm}) *\end{array}$ & pH* & $\begin{array}{c}\text { Titratable } \\
\text { acidity }(\%) *\end{array}$ & $\begin{array}{c}\text { Zone of } \\
\text { inhibition }(\mathrm{mm})\end{array}$ \\
\hline \multirow[t]{4}{*}{24} & $\begin{array}{l}\text { Control (without } \\
\text { carbon source) }\end{array}$ & $5.7 \pm 0.01$ & $0.27 \pm 0.03$ & - & $5.6 \pm 0.21$ & $0.20 \pm 0.01$ & - \\
\hline & $1 \%$ pectin & $5.6 \pm 0.35$ & $0.36 \pm 0.01$ & $5.6 \pm 0.35$ & $5.6 \pm 0.03$ & $0.38 \pm 0.00$ & $6.5 \pm 0.35$ \\
\hline & $2 \%$ pectin & $5.6 \pm 0.07$ & $0.31 \pm 0.05$ & $8.6 \pm 0.28$ & $5.5 \pm 0.02$ & $0.48 \pm 0.03$ & $9.4 \pm 0.23$ \\
\hline & $3 \%$ pectin & $5.6 \pm 0.07$ & $0.46 \pm 0.02$ & $12.3 \pm 0.35$ & $5.4 \pm 0.07$ & $0.66 \pm 0.01$ & $13.3 \pm 0.35$ \\
\hline \multirow[t]{4}{*}{48} & control & $4.9 \pm 0.07$ & $0.78 \pm 0.00$ & - & $4.7 \pm 014$ & $0.49 \pm 0.01$ & - \\
\hline & $1 \%$ pectin & $4.9 \pm 0.01$ & $0.80 \pm 0.07$ & $8.2 \pm 0.42$ & $4.7 \pm 0.07$ & $0.81 \pm 0.00$ & $8.2 \pm 0.42$ \\
\hline & $2 \%$ pectin & $4.6 \pm 0.00$ & $0.81 \pm 0.11$ & $14.3 \pm 0.35$ & $4.3 \pm 0.07$ & $0.88 \pm 0.00$ & $15.3 \pm 0.27$ \\
\hline & $3 \%$ pectin & $4.2 \pm 0.07$ & $0.96 \pm 0.00$ & $16.6 \pm 0.42$ & $4 \pm 0.21$ & $0.95 \pm 0.05$ & $18.6 \pm 0.42$ \\
\hline
\end{tabular}

*Values are expressed as Mean $\pm \mathrm{SD}(n=3)$

$\mathrm{pH}$ lowering effect by stimulating lactobacilli. With increase in pectin concentration, there was an increase in lactobacilli cell concentration resulting in increased production of lactic acid that is responsible for reduction in $\mathrm{pH}$. After $24 \mathrm{~h}$ of incubation $\mathrm{LC}$ reduced the $\mathrm{pH}$ of media to $5.6 \pm 0.07$ and $\mathrm{LF}$ reduced to $5.4 \pm 0.07$ at $3 \%$ pectin concentration. After $48 \mathrm{~h}$ of incubation, LC and LF resulted in $\mathrm{pH}$ value of $4.2 \pm 0.07$ and $4.0 \pm 0.21$. LC and LF showed almost similar $\mathrm{pH}$ lowering effect with $\mu_{\mathrm{pH}}$ of 0.009 and $0.007 \mathrm{~h}^{-1}$, respectively.

The vaginal health is maintained by lactobacilli flora in vagina. One of the important self-defense mechanism of vagina against pathogen is its acidic $\mathrm{pH}$ in the range of 4.0-5.5. Vaginal lactobacilli utilize glycogen in epithelial cells to produce lactic acid that helps to maintain vaginal $\mathrm{pH}$. The presence of lower $\mathrm{pH}$ and lactic acid would restrict the growth of pathogens without affecting the normal flora. The lower $\mathrm{pH}$ values by LC and LF at increasing pectin concentration are indicative of prebiotic potential of pectin.

\subsection{Antimicrobial Activity Against $E$. coli and $C$. albicans}

The antimicrobial activity of supernatants obtained after treatment of growth medium for LC and LF was tested against $E$. coli and $C$. albicans [Table 1 and Figure 5]. The inhibition zone changed as function of time for E. coli. With increase in the incubation time of LC and LF, there was an increase in zone of inhibition against $E$. coli. After 24 of incubation of LC and LF, the zones of inhibition for E. coli were $12.3 \pm 0.35$ and $13.3 \pm 0.85 \mathrm{~mm}$, respectively, whereas after $48 \mathrm{~h}$ of incubation values of $16.6 \pm 0.42$ and $18.6 \pm 0.40 \mathrm{~mm}$ were observed. Thus, the activity was significant against $E$. coli but no zones were observed against $C$. albicans for both lactobacilli strains. The activity against $E$. coli could be attributed to ability of lactobacilli to produce bacteriocin-like substance that prevent the growth of pathogenic bacteria but do not show any effect on itself (lactobacilli). Moreover, E. coli being a Gram-negative bacteria which is known to be more sensitive to bacteriocin. C. albicans, being a yeast, is resistant to this bacteriocin-like substance resulting in no zone of inhibition. This is consistent with the reports of our previous study [20].

Inhibitory zones of LF were larger as compared to that of LC. The bacteriocin produced by different Lactobacilli species could have a different mode of action against $E$. coli showing different zones of inhibition.

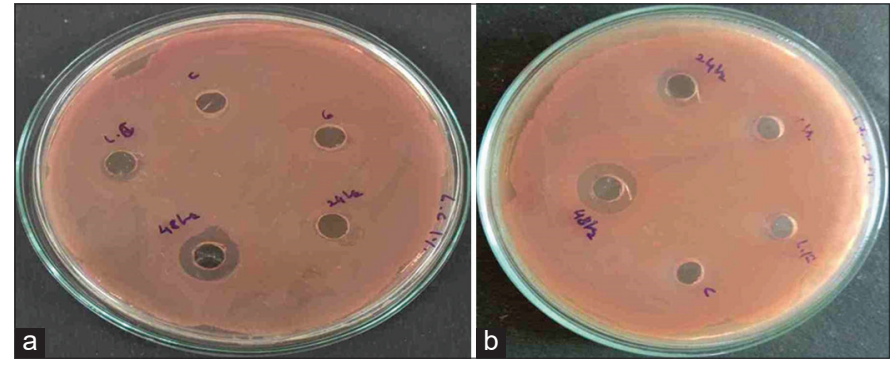

Figure 5: Zone of inhibition of (a) Lactobacilli casei (b) Lactobacilli fermentum supernatants against Escherichia coli.

\subsection{In Vitro Efficacy of Pectin Using Mixed Culture Technique}

The mixed culture or co-culture technique was performed to study the selective nature of pectin as a prebiotic toward the healthy vaginal bacteria like lactobacilli against pathogens, such as $E$. coli and $C$. albicans, in a mixed or co-culture mimicking the in vivo conditions. The cultures of LC or LF with E. coli or C. albicans were grown in MEM supplemented with pectin. The effect of pectin on the viable count of lactobacilli and E. coli or C. albicans was studied [Figures 6-9]. The stimulate effect of pectin on lactobacilli count was evident from the study. After $24 \mathrm{~h}$ of incubation with pectin, there was an increase in the viable count of both LF and LC by $1-2 \log$ values. No inhibitory effect of C. albicans or E. coli was found on lactobacilli. However, there was a significant reduction $(P<0.001)$ in the viable count of $E$. coli as well as $C$. albicans in the presence of pectin and lactobacilli. In the presence of LC and pectin, the initial microbial count of $6.98 \pm 0.32 \mathrm{log} \mathrm{cfu} / \mathrm{ml}$ of $E$. coli decreased to $6.92 \pm 0.62 \log \mathrm{cfu} / \mathrm{ml}$ and $4.84 \pm 0.71 \log \mathrm{cfu} / \mathrm{ml}$ [Figure 6] in $24 \mathrm{~h}$ and $48 \mathrm{~h}$, respectively. E. coli microbial count of $8.09 \pm 0.20 \log \mathrm{cfu} / \mathrm{ml}$, was decreased to $5.05 \pm 0.15 \log \mathrm{cfu} / \mathrm{ml}$ in $24 \mathrm{~h}$ and $5.04 \pm 0.19 \log \mathrm{cfu} / \mathrm{ml}$ in $48 \mathrm{~h}$ when incubated with $\mathrm{LF}$ [Figure 7].

Vaginal lactobacilli play a vital role in maintaining acidic $\mathrm{pH}$ of vagina. The epithelial glycogen in vagina is utilized by lactobacilli flora to produce lactic and acetic acid by fermentation. This helps as defense mechanism of vagina against pathogen. The lower acidic $\mathrm{pH}$ of vagina reduces the risk of pathogenic microbes allowing restoration of the vaginal ecosystem. In addition, lactobacilli are known to compete with the pathogen for the same carbon source and produce antimicrobial 


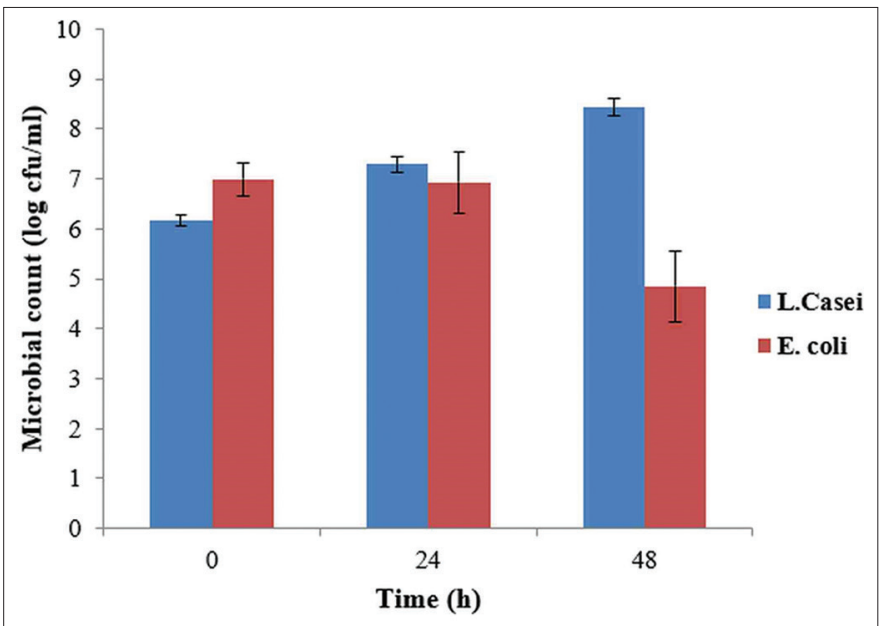

Figure 6: Effect of pectin on viability count of Lactobacilli casei and Escherichia coli in mixed culture. *Error bars represent standard deviations of three replicates.

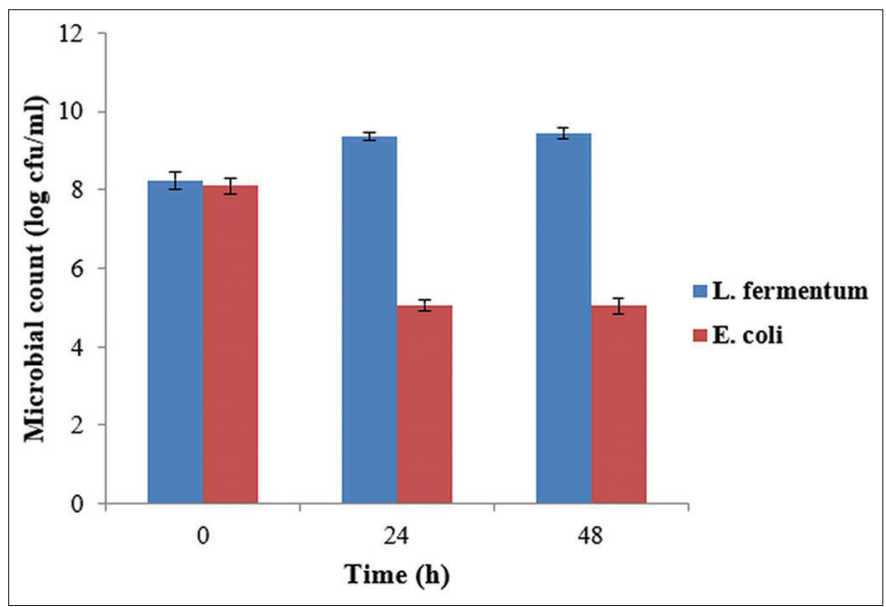

Figure 7: Effect of pectin on viability count of Lactobacilli fermentum and Escherichia coli in mixed culture. *Error bars represent standard deviations of three replicates.

substances such as bacteriocin and hydrogen peroxide that provide unfavorable conditions for the growth of pathogen [20]. Prebiotic does not have a direct effect on pathogens but stimulates the growth of healthy microorganisms like lactobacilli and helps to restore the normal flora.

E. coli is a typical inhabitant of human microflora and is known to cause many infections, including genitourinary tract infections. The inhibition of $E$. coli by lactobacilli is attributed to decrease in $\mathrm{pH}$ due to production of lactic acid as well secretion of bacteriocin-like substance with antimicrobial activity. This is consistent with the study by Tomás et al. [34], who have reported the inhibition of $E$. coli growth in L. acidophilus and E. coli mixed culture.

From Figures 8 and 9, the effect of LF and LC on C. albicans is evident. In $24 \mathrm{~h}$ of incubation, C. albicans count decreased from 7.86 $\pm 0.28 \mathrm{log} \mathrm{cfu} / \mathrm{ml}$ to $4.77 \pm 0.31 \mathrm{log} \mathrm{cfu} / \mathrm{ml}$ and after $48 \mathrm{~h}$, reduction in microbial count was $4.53 \pm 0.18 \log \mathrm{cfu} / \mathrm{ml}$ in the presence of pectin

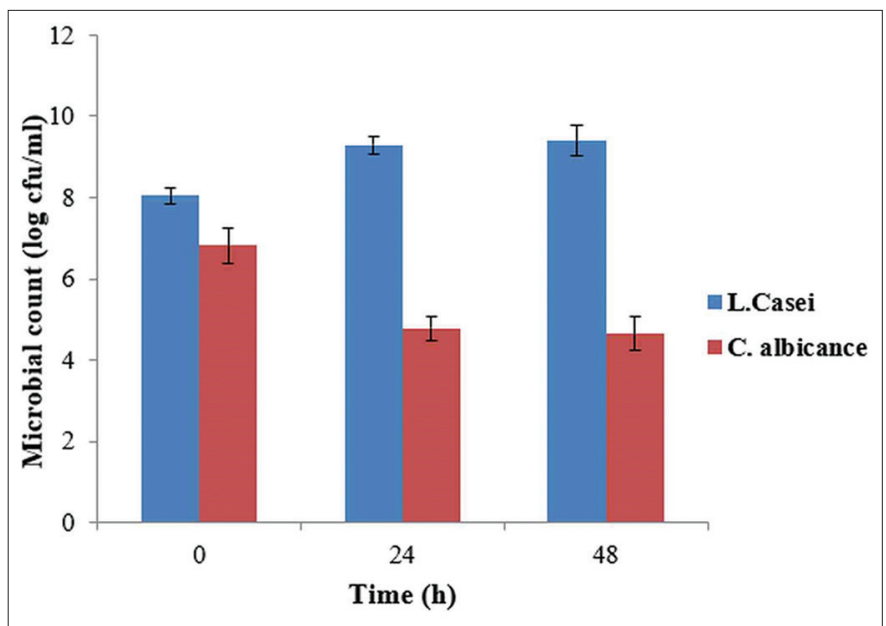

Figure 8: Effect of pectin on viability count of Lactobacilli casei and Candida albicans in mixed culture. *Error bars represent standard deviations of three replicates.

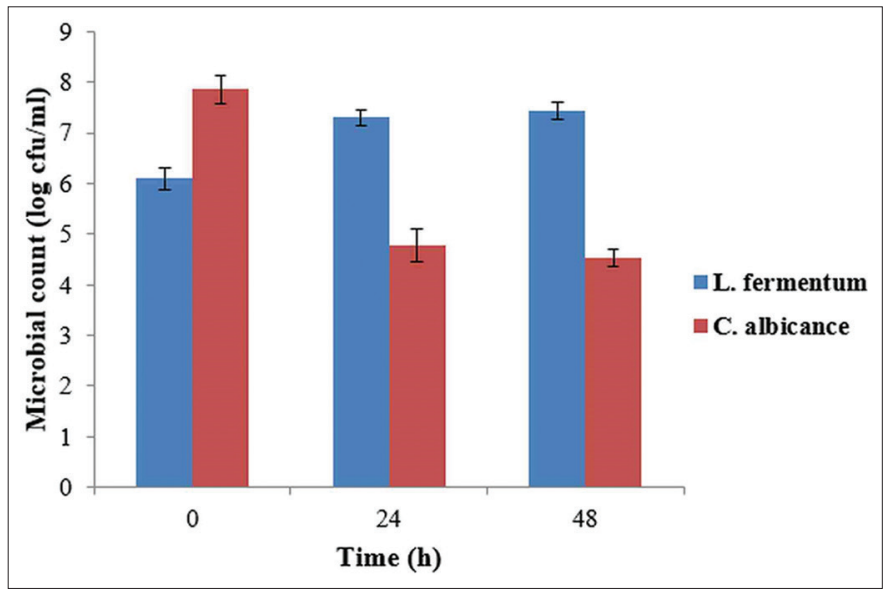

Figure 9: Effect of pectin on viability count of Lactobacilli fermentum and Candida albicans in mixed culture. *Error bars represent standard deviations of three replicates.

and LF. In presence of LC, decrease in C. albicans was from $6.81 \pm$ $0.45 \mathrm{log} \mathrm{cfu} / \mathrm{ml}$ to $4.65 \pm 0.42 \mathrm{log} \mathrm{cfu} / \mathrm{ml}$ in $48 \mathrm{~h}$ of incubation. These results are in contrast to the antimicrobial effects of supernatants of lactobacilli where no effects were observed. The higher anti-candida effect of pectin in a co-culture could be attributed to synbiotic effect of pectin and lactobacilli [28]. The acidic environment provided due to growth of lactobacilli could be one of the reasons responsible for unfavorable conditions for the growth of $C$. albicans, resulting in reduction in its count.

\subsection{In Vivo Effect of Pectin on Vaginal Lactobacilli}

In vivo effect of pectin on vaginal lactobacilli was studied using rat model with compromised vaginal microflora. Rat model was selected for this study because similar to human, in rats Lactobacilli spp. are the major component of vaginal microflora, making local vaginal $\mathrm{pH}$ lower than neutral in contrast to mice where lactobacilli are not dominant species of vaginal flora [35]. 


\subsubsection{Preventive effect}

After pre-treatment of rat vagina with pectin gel for 28 days, the lactobacilli count in vaginal flora was observed as $7.31 \pm 0.89 \log$ $\mathrm{cfu} / \mathrm{ml}$ [Figure 10]. After 3 days of metronidazole gel treatment $\left(\mathrm{T}_{31}\right)$, the lactobacilli count of the control group reduced to $5.32 \pm 0.07 \mathrm{log}$ $\mathrm{cfu} / \mathrm{ml}$ which further decreased to $3.36 \pm 0.28 \log \mathrm{cfu} / \mathrm{ml}$ in 7 days

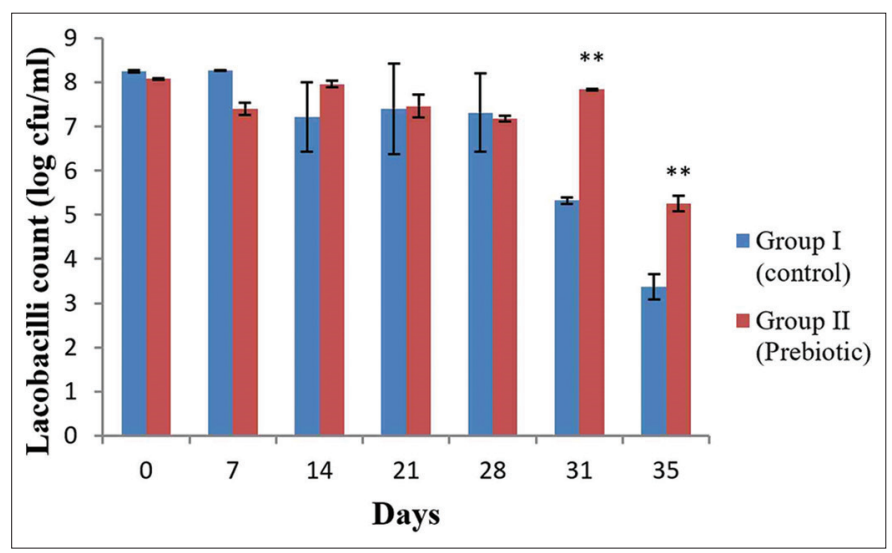

Figure 10: Prophylactic effect of pectin on rat vaginal microflora. *Error bars represent standard deviations of six replicates, ** First 28 days indicate pectin treatment, $31^{\text {st }}$ and $35^{\text {th }}$ day indicates $3^{\text {rd }}$ and $7^{\text {th }}$ day of metronidazole gel treatment.

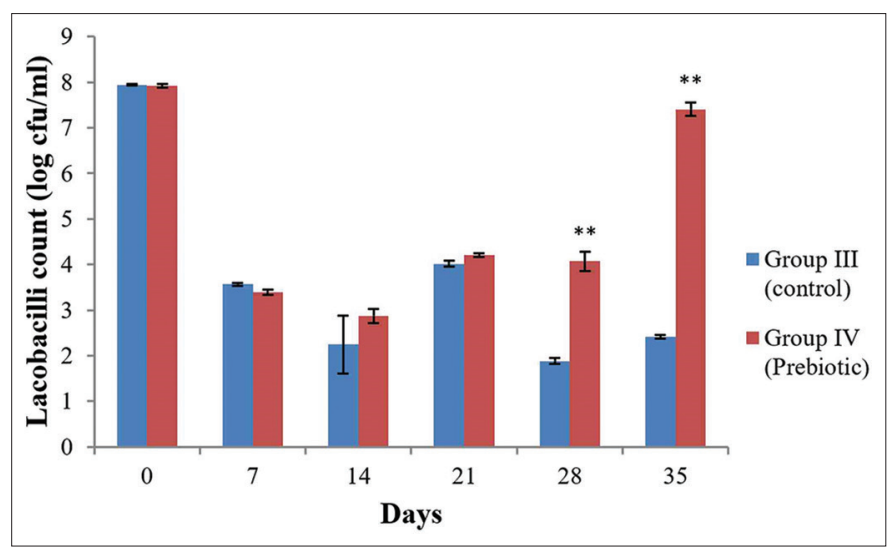

Figure 11: Therapeutic effect of pectin on rat vaginal microflora. *Error bars represent standard deviations of six replicates, ** First 7 days indicate metronidazole gel treatment, $14^{\text {th }}, 21^{\text {st }}, 28^{\text {th }}$, and $35^{\text {th }}$ indicate $7^{\text {th }}, 14^{\text {th }}, 21^{\text {st }}$, and $28^{\text {th }}$ day of pectin treatment.
$\left(T_{35}\right)$. The reduction in lactobacilli count indicated the compromised or disturbed microflora of rat vagina in control groups. The rats, pretreated with pectin (Group 2) showed a significantly lower reduction in lactobacilli count $(5.25 \pm 0.17 \mathrm{log} \mathrm{cfu} / \mathrm{ml}$ after 7 days of metronidazole treatment) than control $(P<0.0001)$. This demonstrated the preventive effect of pectin as prebiotic on vaginal lactobacilli. Various preclinical as well as clinical reports support the prophylactic effects of lactobacilli strains against experimental and urogenital infections in human [36,37]. Prebiotic stimulates the effect of lactobacilli and has shown to produce significant prophylactic effects against infection.

\subsubsection{Therapeutic effect}

For investigating therapeutic effect of pectin, the pectin gel was administered to rats whose vaginal microflora was compromised by administering Metronidazole gel intravaginally for 7 days. The viable count $(3.39 \pm 0.05 \log \mathrm{cfu} / \mathrm{ml})$ after 7 days, confirmed the reduction in vaginal lactobacilli [Figure 11]. When the rats were treated with pectin gel intravaginally for 28 days, there was gradual increase in lactobacilli count after 14 days of treatment $\left(\mathrm{T}_{21}\right)$. The control group did not show any improvement in lactobacilli count. Few rats also showed signs of fungal infection. This could be due to reduction in vaginal lactobacilli resulting in a compromised vaginal defense mechanism leading to dysbiosis. After 28 days of prebiotic treatment $\left(\mathrm{T}_{35}\right)$, there was a complete restoration of vaginal flora (lactobacilli count, $7.40 \pm 0.14 \log \mathrm{cfu} / \mathrm{ml}$ ). The control group (group 3) did not show any signs of improvement and the presence of fungal infection was observed. After 28 days $\left(\mathrm{T}_{35}\right)$, lactobacilli count was $2.41 \pm 0.03$ $\log \mathrm{cfu} / \mathrm{ml}$ in control group. This demonstrated significant faster recovery $(P<0.0001)$ or restoration of microflora in the case of prebiotic treatment.

\subsection{Histopathology of Vagina}

Microscopic examination of vaginal tissues of rats from the control group did not reveal any signs of vaginal irritation [Figure 12]. Rats of metronidazole treated group revealed multifocal mild hyperplasia of squamous epithelium, multifocal mild vasodilation, and multifocal moderate lymphocytic infiltration at lamina propria and epithelium. Histopathological evaluation of group treated with metronidazole followed by pectin revealed focal mild hyperplasia of squamous epithelium and focal mild vasodilation and very mild lymphocytic infiltration at lamina propria. The improvement in the signs of irritation, caused by Metronidazole gel, was observed after 28 days of pectin treatment.

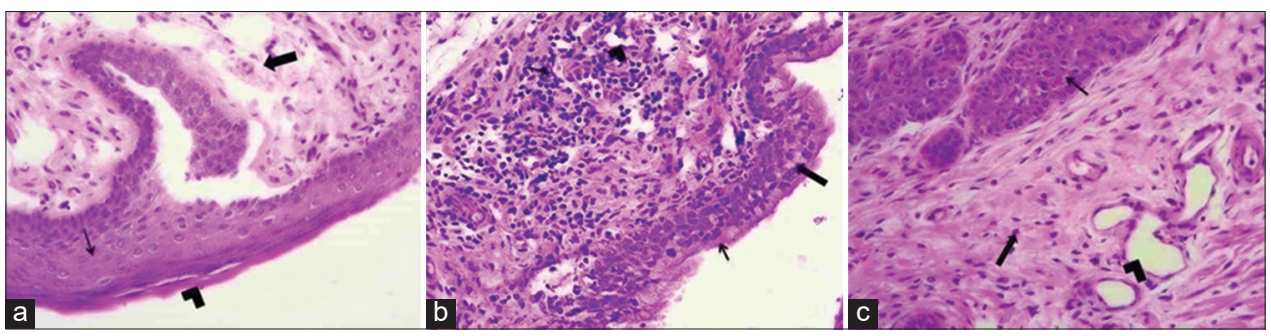

Figure 12: Histopathology of (a) control (normal vagina) showing normal histology, Stratified squamous epithelium (small arrow), keratinized cells (arrowhead), lamina (large arrow) $\{\mathrm{H} \& \mathrm{E}, 400 \mathrm{X}\}$. (b) Metronidazole treated vagina: showing normal histology, hyperplasia of squamous epithelium (small arrow), moderate lymphocytic infiltration at lamina (large arrow) $\{\mathrm{H} \& \mathrm{E}, 400 \mathrm{X}\}$. (c) Metro + pectin treated vagina: Showing mild lymphocytic infiltration at lamina (small arrow) 


\section{CONCLUSION}

The study was designed to investigate the prebiotic potential of pectin on vaginal lactobacilli. Pectin showed stimulative in vitro effect of pectin on LC and LF growth that is indigenous strains of human vagina. Increase in pectin concentration showed a decrease in $\mathrm{pH}$, increase in lactic acid production, and potential antimicrobial effect against $E$. coli. Mixed culture study showed stimulative effect of pectin on LC and LF and significant inhibitory effect on E. coli and C. albicans. In vivo studies in rat demonstrated prophylactic and curative effect of pectin as prebiotic on vaginal lactobacilli flora. The study indicated the prebiotic potential of pectin for prophylactic and therapeutic effect in vagina.

\section{ACKNOWLEDGMENT}

Authors are thankful to the Department of Biotechnology, Dr. D. Y. Patil Science College, Pune and Department of Microbiology, Dr. D.Y. Patil Medical College, Pune, for providing microbial cultures. The authors also acknowledge the kind support of Krishna Pectin Jalgaon, India, for providing gift sample of citrus fruit pectin.

\section{FINANCIAL SOURCE OF SUPPORT}

None.

\section{CONFLICTS OF INTEREST}

None.

\section{ETHICAL COMMITTEE APPROVAL DETAILS}

All the animal experiments conducted in the present study were approved by Institutional Animal Ethical Committee (Reg no: 198/PO/ $\mathrm{Re} / \mathrm{S} / 2000 / \mathrm{CPCSEA})$. The protocol approval number is DYPIPSR/ IAEC/17-18/P-15. All the experiments were strictly adhering to CPCSEA guidelines, India, and also as per ARRIVE guidelines.

\section{REFERENCES}

1. Klebanoff S, Hillier S, Eschenbach D, Waltersdorph A. Control of the microbial flora of the vagina by $\mathrm{H}_{2} \mathrm{O}_{2}$-generating lactobacilli. J Infect Dis 1991;164:94-100.

2. Menard J. Antibacterial treatment of bacterial vaginosis: Current and emerging therapies. Int J Womens Health 2011;3:295-305.

3. Alvarez-Olmos M, Oberhelman R. Probiotic agents and infectious diseases: A modern perspective on a traditional therapy. Clin Infect Dis 2001;32:1567-76.

4. Al-Ghazzewi F, Tester R. Biotherapeutic agents and vaginal health. J Appl Microbiol 2016;121:18-27.

5. Aldunate M, Srbinovski D, Hearps A, Latham C, Ramsland P, Gugasyan R, et al. Antimicrobial and immune modulatory effects of lactic acid and short chain fatty acids produced by vaginal microbiota associated with eubiosis and bacterial vaginosis. Front Physiol 2015;6:164.

6. Vyas U, Ranganathan N. Probiotics, prebiotics, and synbiotics: Gut and beyond. Gastroenterol Res Pract 2012;2012:872716.

7. Saad N, Delattre C, Urdaci M, Schmitter J, Bressollier P. An overview of the last advances in probiotic and prebiotic field. LWT Food Sci Technol 2013;50:1-16.

8. Lin Y, Thibodeaux C, Pena J, Ferry G, Versalovic J. Probiotic Lactobacillus reuteri suppress proinflammatory cytokines via c-Jun. Inflamm Bowel Dis 2008;14:1068-83.

9. Sartor R, Probiotic therapy of intestinal inflammation and infections.
Curr Opin Gastroenterol 2005;21:44-50.

10. Liong M. Roles of probiotics and prebiotics in colon cancer prevention: Postulated mechanisms and in-vivo evidence. Int J Mol Sci 2008;9:854-63.

11. Hilton E, Isenberg H, Alperstein P, France K, Borenstein M. Ingestion of yogurt containing Lactobacillus acidophilus as prophylaxis for candidal vaginitis. Ann Intern Med 1992;116:353-7.

12. Coste I, Judlin P, Lepargneur J, Bou-Antoun S. Safety and efficacy of an intravaginal prebiotic gel in the prevention of recurrent bacterial vaginosis: A randomized double-blind study. Obstet Gynecol Int 2012;2012:147867.

13. Homayouni A, Bastani P, Ziyadi S, Alizadeh-Charandabi SM, Ghalibaf M, Mortazavian A, et al. Effects of probiotics on the recurrence of bacterial vaginosis: A review. J Low Genit Tract Dis 2014;18:79-86.

14. Falagas M, Betsi G, Athanasiou S. Probiotics for prevention of recurrent vulvovaginal candidiasis: A review. J Antimicrob Chemother 2006;58:266-72.

15. Borchert D, Sheridan L, Papatsoris A, Faruquz Z, Barua J, Junaid I, et al. Prevention and treatment of urinary tract infection with probiotics: Review and research perspective. Indian J Urol 2008;24:139-44.

16. Cribby S, Taylor M, Reid G. Vaginal microbiota and the use of probiotics. Interdiscip Perspect Infect Dis 2008;2008:256490.

17. Raman M, Ambalam P, Kondepudi K, Pithva S, Kothari C, Patel A, et al. Potential of probiotics, prebiotics and synbiotics for management of colorectal cancer. Gut Microbes 2013;4:181-92.

18. Sutherland A, Tester R, Al-Ghazzewi F, McCulloch E, Connolly M. Glucomannan hydrolysate (GMH) inhibition of Candida albicans growth in the presence of Lactobacillus and Lactococcus species. Microb Ecol Health Dis 2008;20:127-34.

19. Rousseau V, Lepargneur J, Roques C, Remaud-Simeon M, Paul F. Prebiotic effects of oligosaccharides on selected vaginal lactobacilli and pathogenic microorganisms. Anaerobe 2005;11:145-53.

20. Mahore J, Bhavana R, Deshkar S. Investigation of oligosaccharides for prebitoic action on vaginal lactobacilli. J Young Pharm 2017;9:502-6.

21. Palanisamy K, Aravind E, Dhivya J, Kuppamuthu K. Extraction and analysis of pectin from citrus peels: Augmenting the yield from citrus Limon using statistical experimental design. Iran J Energy Environ 2014;5:303-12.

22. Luzio G, Cameron R. Determination of degree of methylation of food pectins by chromatography. J Sci Food Agric 2013;93:2463-9.

23. Chung W, Meijerink M, Zeuner B, Holck J, Louis P, Meyer A, et al. Prebiotic potential of pectin and pectic oligosaccharides to promote anti-inflammatory commensal bacteria in the human colon. FEMS Microbiol Ecol 2017;93:127.

24. Morris G, Kok S, Harding S, Adams G. Polysaccharide drug delivery systems based on pectin and chitosan. Biotechnol Genet Eng Rev 2010;27:257-84.

25. Farinha L, Porto M, Souza E, Oliveira M, Oliveira R. Influence of prebiotic ingredients on the growth kinetics and bacteriocin production of Lactococcus lactis. Chem Eng Trans 2015;43:313-8.

26. Aslim B, Kilic E. Some probiotic properties of vaginal lactobacilli isolated from healthy women. Jpn J Infect Dis 2006;59:249-53.

27. Riaz S, Nawaz SK, Hasnain $\mathrm{S}$. Bacteriocins produced by $L$. fermentum and L. acidophilus can inhibit cephalosporin resistant $E$. coli. Braz J Microbiol 2010;41:643-8.

28. Fooks LJ, Gibson GR. In vitro investigations of the effect of probiotics and prebiotics on selected human intestinal pathogens. FEMS Microbiol Ecol 2002;39:67-75.

29. Matthews A, Grimaldi A, Walker M, Bartowsky E, Grbin P, Jiranek V. Lactic acid bacteria as a potential source of enzymes for use in vinification. Appl Environ Microbiol 2004;70:5715-31. 
30. Zhang S, Hu H, Wang L, Liu F, Pan S. Preparation and prebiotic potential of pectin oligosaccharides obtained from citrus peel pectin. Food Chem 2018;244:232-7.

31. Almstahl A, Lingstrom P, Eliasson L, Carlen A. Fermentation of sugars and sugar alcohols by plaque lacotbacillus strains. Clin Oral Invest 2013; 17:1465-70.

32. Delgado S, Leite A, Ruas-Madiedo P, Mayo B. Probiotic and technological properties of Lactobacillus spp. strains from the human stomach in the search for potential candidates against gastric microbial dysbiosis. Front Microbial 2014;5:766.

33. Piwat S, Teanpaisan R, Dahlen G, Thitasomakul S, Douglas CW. Acid production and growth by oral Lactobacillus species in vitro. $\mathrm{J}$ Investig Clin Dent 2012;3:56-61.

34. Tomás MJ, Ocaña V, Wiese B, Nader-Macías M. Growth and lactic acid production by vaginal Lactobacillus acidophilus CRL 1259, and inhibition of uropathogenic Escherichia coli. J Med Microbiol
2003;52:1117-24.

35. Cassone A, Sobel J D. Experimental models of vaginal candidiasis and their relevance to human candidiasis. Infect Immun 2016;84:1255-61.

36. Lee J, Lee J, Sung S, Lee S. Preventive effects of Lactobacillus mixture on experimental $E$. coli urinary tract infection in infant rats. Yonsei Med J 2013;54:489-93.

37. Liliana $\mathrm{P}$, Walter $\mathrm{G}$, Isabel L. Vaginal colonization and activity of the probiotic bacterium Lactobacillus fermentum L23 in a murine model of vaginal tract infection. J Med Microbiol 2010;59:360-4.
How to cite this article:
Deshkar SS, Ahire KS, Mahore JG. In vitro and in vivo evaluation of prebiotic potential of pectin on vaginal lactobacilli. J App Biol Biotech. 2022;10(01):103-111. 